\title{
Commentary: Lobectomy or sublobar resection for early lung cancer: One small step for surgeons, one giant step for patients
}

\author{
Nasser Altorki, MD, and Ben Lee, MD
}

\footnotetext{
From the Division of Thoracic Surgery, Department of Cardiothoracic Surgery, Weill Cornell Medicine-New York Presbyterian Hospital, New York, NY

Disclosures: Authors have nothing to disclose with regard to commercial support.

Received for publication April 1, 2019; accepted for publication April 1, 2019; available ahead of print May 31, 2019.

Address for reprints: Nasser Altorki, MD, Division of Thoracic Surgery, Department of Cardiothoracic Surgery, Weill Cornell Medicine-New York Presbyterian Hospital, New York, NY 10021 (E-mail: nkaltork@med. cornell.edu).

J Thorac Cardiovasc Surg 2019;158:909-10

$0022-5223 / \$ 36.00$

Copyright $(2019$ by The American Association for Thoracic Surgery

https://doi.org/10.1016/j.jtcvs.2019.04.010
}

The randomized trial conducted by the Lung Cancer Study Group between 1982 and 1988 established lobar resection (LR) rather than sublobar resection (SLR) as the standard of care for peripheral T1N0 non-small cell lung cancer (NSCLC). Merely a decade later, the trial's results were challenged by the advent of advanced imaging and staging modalities that led to the detection of smaller and perhaps more curable tumors, as well as by an increase in the elderly segment of the population who may be better served by SLR. The debate has resulted in 2 separate large randomized clinical trials, a North American trial (Alliance/ CALGB 140503) and a Japanese trial (JCOG/WJOG 0802) both seeking to test the hypothesis that SLR is noninferior to LR for peripheral clinically node negative tumors $2 \mathrm{~cm}$ or less. Both trials have completed accrual, and long-term oncologic results are forthcoming. Although the primary end points of both trials have not matured yet, reporting of secondary end points, particularly those related to patient safety such as perioperative mortality and adverse events, is of great interest to patients, their treating physicians, and possibly to third-party payers.

In the current issue of the Journal, Suzuki and colleagues ${ }^{1}$ report the safety results from the JCOG 0802, which to our knowledge is the largest randomized thoracic surgical trial ever reported. Although the trial was not specifically designed to compare perioperative outcomes, the results are truly outstanding by any conceivable metric. Among 552 patients who had a segmentectomy and 554 patients who had a LR, there was no treatment-related mortality at either 30 or 90 days. Adverse events grade 2 or greater occurred in $27.4 \%$ and $26.2 \%$ of patients, respectively. These excellent perioperative outcomes along with those recently reported by Alliance/CALGB $140503^{2}$ set a contemporary and notable benchmark for surgical outcomes after LR or SLR for early-stage NSCLC, which can only be a big win for patients. In the aftermath of these

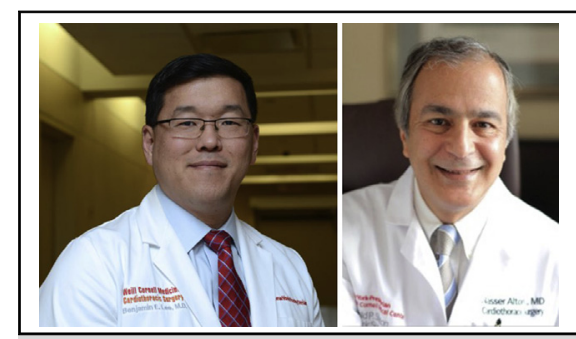

Ben Lee, MD, and Nasser Altorki, MD

Central Message

In the largest randomized trial comparing lobectomy with segmentectomy for early-stage lung cancer, there was no treatment-related 30 - or 90-day mortality and very low perioperative morbidity.

See Article page 895 .

2 large trials and the results of American College of Surgery Oncology Group Z0030, ${ }^{3}$ quoting a surgical mortality of $4 \%$ to $5 \%$ can no longer represent an objective representation of surgical outcomes for early-stage NSCLC.

In our opinion, an interesting and potentially problematic concept proposed by the authors is the classification of segmental resections into simple and complex. The oncologic ramifications of that distinction will perhaps be elucidated with maturation of the primary end point. However, from an immediate surgical point of view, it is unclear to us whether a complex segmentectomy requires an open rather than a minimally invasive approach. It is conceivable that a greater proportion of complex segmentectomies were performed by open thoracotomy because of increased technical difficulty. Accordingly, will some of the benefits gained from segmentectomy be lost as a result of the increased morbidity of thoracotomy? More importantly, would a small peripheral lesion that requires a complex segmentectomy be more easily removed by a large wedge resection without compromising the oncologic outcome? Although JCOG0802 only compared segmentectomy with lobectomy, the SLR arm in Alliance/CALGB 140503 allowed for both segmental and wedge resection to be done. We await, on tenterhooks, the long-term results of both of these trials because they may provide answers to these and other questions that will affect surgical care for NSCLC for decades to come. 


\section{References}

1. Suzuki K, Saji H, Aokage K, Watanabe S-I, Okada M, Mizusawa J, et al. Comparison of pulmonary segmentectomy and lobectomy: safety results of a randomized trial. J Thorac Cardiovasc Surg. 2019;158:895-907.

2. Altorki NK, Wang X, Wigle D, Gu L, Darling G, Ashrafi AS, et al. Perioperative mortality and morbidity after sublobar versus lobar resection for early-stage non-small-cell lung cancer: post-hoc analysis of an international, randomised, phase 3 trial (CALGB/Alliance 140503). Lancet Respir Med. 2018;6:915-24

3. Allen MS, Darling GE, Pechet TT, Mitchell JD, Herndon JE II, Landreneau RJ, et al; ACOSOG Z0030 Study Group. Morbidity and mortality of major pulmonary resections in patients with early-stage lung cancer: initial results of the randomized, prospective ACOSOG Z0030 trial. Ann Thorac Surg. 2006;81: 1013-9. 